\title{
The Use of Novel Camtasia Videos to Improve Performance of At-Risk Students in Undergraduate Physiology Courses
}

\author{
Cynthia J. Miller ${ }^{1, *}$ \\ ${ }^{1}$ Department of Biology, Valencia College, Kissimmee, Florida, USA \\ *Correspondence: Department of Physiology \& Biophysics, School of Medicine, University of Louisville, HSC \\ A-1115, 500 S. Preston St., Louisville, KY 40292, USA. Tel: 1-502-852-7562. E-mail: cjmill04@louisville.edu
}

Received: January 8, $2014 \quad$ Accepted: January 20, $2014 \quad$ Online Published: February 6, 2014

doi:10.5430/wje.v4n1p22ＵRL: http://dx.doi.org/10.5430/wje.v4n1p22

\begin{abstract}
Students in undergraduate physiology courses often have difficulty understanding complex, multi-step processes, and these concepts consume a large portion of class time. For this pilot study, it was hypothesized that online multimedia resources may improve student performance in a high-risk population and reduce the in-class workload. A narrated Camtasia video was created using PowerPoint slides of a cardiomyocyte action potential. Historically, student performance on an exam essay for this topic was very poor following a traditional didactic lecture (class avg. of $64 \%$ ). Replacement of lecture on the topic with an online video improved the class avg. on the essay by $6 \%$ and the class median by $8 \%$ ( $n=198$, 9 course sections). While this effect was not shown to be statistically significant ( $\mathrm{p}=0.1$, Student's t-test) due to a large variability in scores, it nonetheless indicated a general positive effect on student performance. Furthermore, the video appeared to have a large influence on lower-performing students, reducing the percentage of failing students on the essay from $38 \%$ with traditional lecture to $24 \%$ with access to the video. Anonymous polling of the students indicated the video was helpful in visualizing the process and allowing repetition of material. While creation of multimedia resources may require significant instructor preparation time, these results suggest that the time invested may be advantageous to student success, particularly for at-risk students.
\end{abstract}

Keywords: multimedia, online learning, hybrid, science, undergraduate

\section{Introduction}

Today's college professor faces a multitude of pressures from students, administration, and their colleagues. Modern students of the millennial generation are requesting updates in technology and a movement to online resources. The use of these resources must be reconciled with the "content pressure" from colleges and universities to ensure that the appropriate topics are covered. This is further compounded by fellow professors emphasizing a need for active learning techniques and alternative content delivery methods.

While each of these components is important to student success, they must also be balanced with the realities of contact hours and course length. This leaves many professors wishing at the end of the semester for more time with students. Consequently, faculty members are turning to supplemental online resources or hybrid courses in order to reconcile the time constraints of modern classroom scheduling with outside pressures. Hybrid courses, also referred to as blended courses, consist of a mixture of face-to-face class time with online lectures, assignments, discussions or other web-based instructional technologies (Sowan \& Jenkins, 2013). Hybrid courses have been shown to increase student performance in physiology coursework by an average of one letter grade (McFarlin, 2008). Research indicates that web-based learning increases student preparation, confidence, retention of knowledge, problem-solving abilities, and engagement. (Chumley-Jones, Dobbie, \& Alford, 2002; Goldberg, Haase, Shoukas, \& Schramm, 2006; Lin, Liang, \& Tsai, 2012; Miller, Aiken, \& Metz, “in press”). Furthermore, hybrid science classes have been reported to foster a more positive experience than traditional lecture-based classes, with an improvement in professor-student interactions and group dynamics (Riffell \& Sibley, 2005). By moving some portions of the course content online, more in-class time is available for discussion, problem-solving, experimentation, or review.

It is well documented that students have trouble progressing from basic rote memorization of scientific facts to conceptual reasoning and problem-solving (Alberts, 2009). Through personal observation, this has been found to be 
particularly evident in an undergraduate two-semester Anatomy and Physiology course at Valencia College in Orlando, FL. The first semester of Anatomy and Physiology covers systems such as the skeletal and muscular systems that require a great deal of memorization and basic factual knowledge. As students progress to Anatomy and Physiology II courses, there is a movement towards more advanced, multi-factorial concepts such as cardiac and respiratory function. While some students adjust easily to the change, others have difficulty in visualizing the steps of the processes, or in integrating how multiple variables can affect outcomes. Traditional didactic lectures are limited in their ability to address these complicated issues in a timely fashion. Consequently, this puts a large burden on the professors to allocate precious contact hours with struggling students to reinforce the material. Online multimedia materials could thus be advantageous in that they allow the professor to reach many students, and allow for necessary individual repetition of complex material.

During traditional lectures, professors often rely on static PowerPoint images or chalk-talks to present their materials. While these resources are useful in some contexts, they may be poorly suited for dynamic physiological processes. The large body of work by Richard Mayer has examined the usefulness of multimedia resources in the classroom in his cognitive theory of multimedia learning (Mayer, 2009). Videos displaying animations may be advantageous, due to the ability to use visual cues in order to highlight specific components, or to slow down or speed up various processes to emphasize concepts (Hegarty, 2004). Furthermore, multimedia resources can be used to visualize processes that are invisible to the naked eye (Ainsworth \& Van Labeke, 2004). Indeed, a meta-analysis of 26 studies indicated that students taught using instructional animations, as compared to static pictures, were better able to produce mental models, complete problem-solving tasks, and retain information (Hoffler \& Leutner, 2007).

Several studies have been completed on the effectiveness of web-based teaching methods, with mixed results. Some studies have found no performance gains in web-based instruction versus traditional lecture, while others have shown significant improvement (Goldberg \& McKhann, 2000; McFarlin, 2008; Reed, 2003; Woo \& Kimmick, 2000). Review papers of the topic have found that web-based learning results in similar performance gains to other educational methods (Chumley-Jones et al., 2002). Interestingly, while previous studies have focused on the overall effects of using online resources, few studies have focused on which types of students may benefit the most, or the least, from these activities. Different classroom student makeups could thus be a major factor influencing the varying results found in the literature.

At-risk students who are unsuccessful in the typical classroom setting may be more motivated, or comfortable, seeking online help in the course. Several different learner characteristics have been identified as at-risk in the scientific literature. There may be specific academic challenges for undergraduate students who are of a non-traditional age, from racial or ethnic minorities, speak English as a second language, from low socioeconomic status, or have learning disabilities (Duran, 1989; Ely, 1997; Heisserer \& Parette, 2002). A review paper completed by the U.S. Department of Education in 2002 found that computer-assisted instruction did result in an improvement in the performance of at-risk students in the K-12 population (Office of Educational Research and Improvement, 2002). Students performing at a high level may already have established appropriate learning techniques and be unaffected by accessory methods. On the other hand, some evidence suggests that students in higher-level undergraduate classes benefit more from hybrid coursework than freshman. Riffell and Sibley found that freshman students enrolled in hybrid courses versus traditional courses scored the same on post-tests, while upperclassmen had higher performance levels in the hybrid environment (2005). Researchers have hypothesized that more established students may appreciate the flexible schedule of online learning, while freshman may not possess the self-discipline needed to succeed in online learning (Riffell \& Sibley 2005; Sullivan, 2001).

It has been shown that the learning styles of at-risk students differ significantly from those of successful students (Drysdale, Ross, \& Schulz, 2001). The highly visual nature of web-based learning could therefore be more beneficial to some groups of students than others. Thus, it appears that the use of web-based instructional methods should undergo further examination, particularly on the effect that it might have on at-risk students at the undergraduate level. In many community colleges with open admission policies, a large majority of the student population could be classified as at-risk. Based on this unique student population, the goal of this pilot study was to initially determine whether the use of web-based learning was beneficial or harmful to the performance of students who were largely in an at-risk population. It was hypothesized that the use of novel multimedia resources may improve the performance of a high-risk population of students. 


\section{Methods}

\subsection{Participants}

This study was completed at Valencia College, a large, southern, community-based college with approximately 60,000 enrolled students. At this institution, the diverse student body includes a large number of non-traditional students with busy work and home schedules, students with learning disabilities, and students for which English is their second language. In the school year in which this study was completed, 31\% of the student population was reported as Caucasian and $42 \%$ of students were reported as Hispanic (Valencia, 2012). Furthermore, 54\% of students enrolled for credit were 21 or more years of age (Valencia, 2012). Of the entering students, 74\% were required to take preparation-level courses before they were ready for college-level courses (Valencia, 2010). Thus, the population of students at this college could be classified as highly "at-risk" due to their makeup.

The study took place in Anatomy and Physiology II courses, a four-credit hour class that consisted of three hours of didactic lectures per week and three hours of laboratory per week. All students enrolled in the courses had successfully passed Anatomy and Physiology I with a minimum passing grade of $\mathrm{C}$, and class sizes ranged from 15-24 students. This study was completed over the span of four semesters according to the general setup shown in Figure 1. As it was hypothesized that the online videos would be beneficial for at-risk students, a posttest quasi-experimental design was necessary. In this design, current students were taught a portion of the class content using online videos, and their performance was compared to past students who were taught the information using traditional lectures methods. Using this design, it was important to determine that the analyzed groups were similar in makeup.

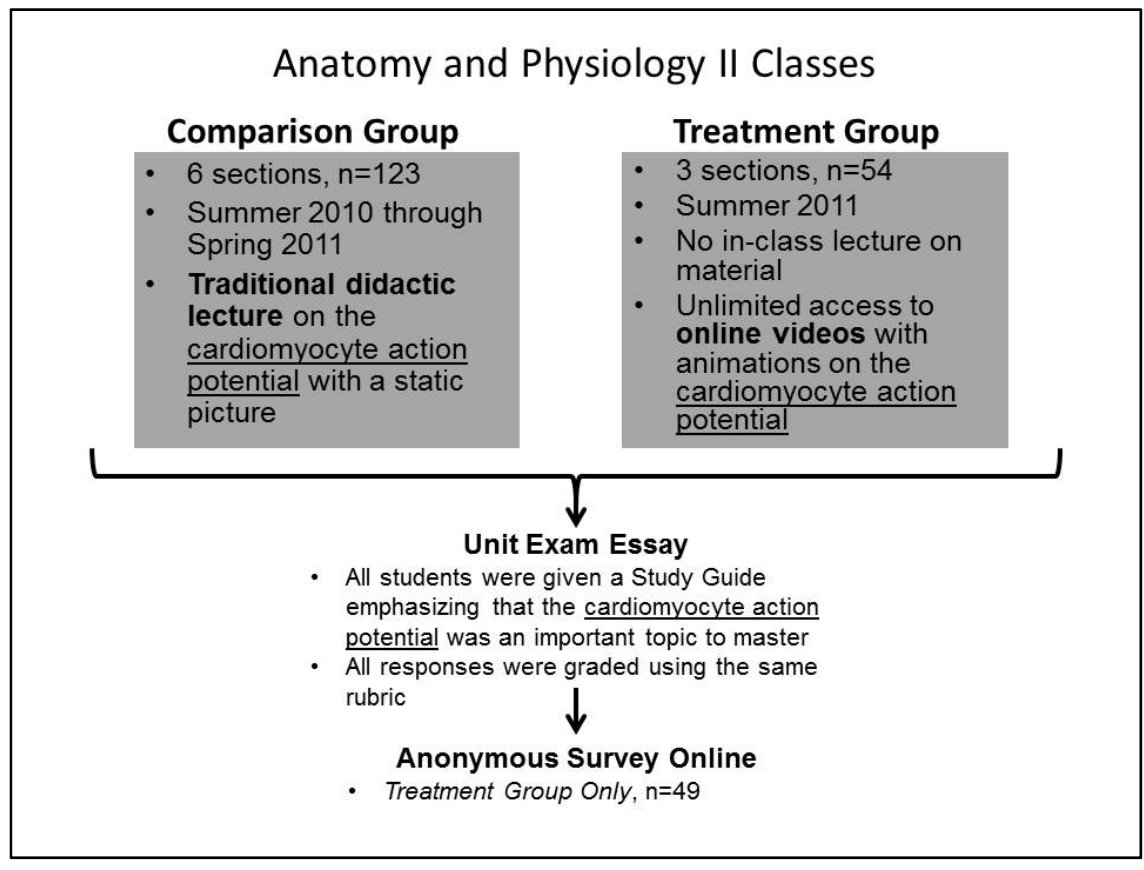

Figure 1. General Setup for the Study

In the experimental group, students were taught about a cardiomyocyte action potential in their Anatomy and Physiology course using online videos. After viewing the videos, student performance was evaluated using an exam essay. The experimental group consisted of three different sections of the course $(n=54)$ in the Summer 2011 semester. Class sizes in the experimental group ranged from 15-22 students, with an average of 18 students per class. The performance of the students taught using online videos was compared to the essay performance in past semesters of the course taught using a traditional didactic lecture. This comparison group $(n=123)$ consisted of six different sections of the course from Summer 2010 through Spring 2011. Class sizes in the comparison group ranged from 18-24 students, with an average of 22 students per class.

In the experimental group, $23 \%$ of the participants were males and $77 \%$ females. Of these students, $47 \%$ reported as Hispanic. In the comparison group $19 \%$ of the participants were males and $81 \%$ females. Of these students, $49 \%$ reported as Hispanic. The high percentage of female participants in upper-level science courses was characteristic of Valencia College due to the high number of female Pre-Nursing students. There were no significant differences 
between the experimental and comparison groups in terms of student age (average of 22 years) or entering GPA from Anatomy \& Physiology I coursework (average of 2.9). The same instructor taught all of the sections in both the experimental and comparison groups, and the curricula was the same for all sections.

\subsection{Instructional Materials}

An animation of the cardiomyocyte action potential was created using PowerPoint. This topic was selected for the study because, historically, student performance on an exam essay for the topic was poor following a traditional didactic lecture (class average of 64\%). The traditional didactic lecture, which lasted approximately 30 minutes, utilized a static PowerPoint image that provided an overview of the cardiomyocyte action potential. In reality, this process is very dynamic, with multiple ions undergoing influx and efflux through the plasma membrane during different phases. Thus, the highly conceptual nature of the topic made it well suited to a multimedia format.

The original PowerPoint slide was used to create a series of animations which displayed the ions involved in the cardiomyocyte action potential, and their direction of movement during each of the phases. These animations were then recorded and narrated in the program Camtasia 7.0 (http://www.techsmith.com/camtasia.html) using the slide show feature. Camtasia is an inexpensive, screen-recording software program which can be used to easily create flash videos (Blevins \& Elton, 2009; Cox, 2004). Two separate videos were created, which were approximately five minutes in duration each. Two videos were created due to students' preference for short video files, and to provide easily downloadable file sizes (Marks, 2004). The cardiomyocyte videos were closed-captioned and ADA-compliant for students with special needs. The videos used in this study were published for use by other institutions in the American Physiological Society Archive of Teaching Resources (Miller, 2012a; Miller, 2012b).

\subsection{Research Design}

Students in the treatment group were not given an in-class lecture on the cardiomyocyte action potential, and their only exposure to this material was via the posted videos or through reading their textbook. The remaining material on the unit exam was covered via a traditional didactic lecture. The cardiomyocyte action potential videos were posted online on the classroom Blackboard website and students were encouraged to access the videos outside of class to obtain the material. The videos were posted as a flash file and the commonly-used Adobe flash player can be downloaded for free online (www.adobe.com). At the beginning of the semester, all students were given an orientation to Blackboard, and $100 \%$ of students had utilized the site to access class notes, announcements, grades, etc. prior to the posting of the videos. In the experimental groups, an announcement was made that a portion of the class content would be available in video form. This was also transmitted via the daily assignments list posted online, as well as a Blackboard announcement. Students were given unlimited access to the videos and online tracking verified that all students viewed the videos at least once over the course of the unit. On average, students accessed the video three times prior to the unit exam. Tracking was necessary to ensure that students were correctly reporting their usage, as discrepancies of up to $20 \%$ have been noted in the literature (Chumley-Jones et al., 2002).

\subsection{Assessment}

Students were tested on the material via a unit exam essay (shown in Figure 2), and their responses were graded using a professor-designed rubric (shown in Figure 3). The rubric was not disclosed to students during the exam. The essay comprised $10 \%$ of a unit exam covering the cardiovascular and immune systems, which also included multiple choice questions, fill-in-the blank questions, and a second essay on a different topic that varied by classes. Historical data from the cardiomyocyte essay in six sections of the course given traditional didactic lectures was compared with the essay performance from three sections of the course which were given access to the videos. In all sections of the class (treatment and comparison) the cardiomyocyte action potential was clearly defined as an important topic through a study guide emphasizing that it was a likely essay topic for the exam. The cardiomyocyte action potential was listed with two other potential essay topics, and it was announced in class and on the study guide that students must be able to thoroughly describe these content areas for success on the unit exam. For consistency, the same professor gave each of the lectures and created the narrations and content for the videos. 


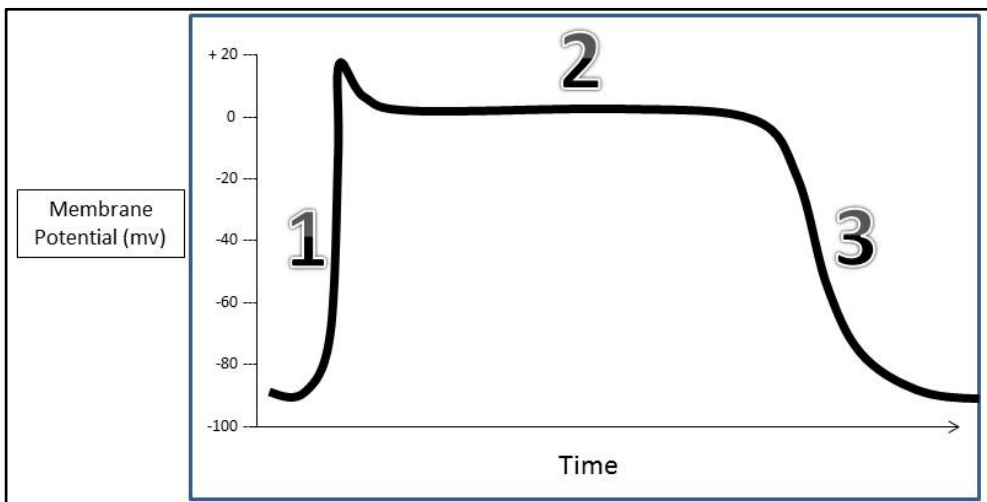

1. Describe in detail which ions are responsible for the 3 phases of the action potential shown above. Your response should include the following terms:

- Calcium $\left(\mathrm{Ca}^{2+}\right)$ - Potassium $\left(\mathrm{K}^{+}\right)$

- Depolarization - Repolarization

- Efflux (out of the cell) - Resting membrane potential

- Influx (into the cell) - Sodium $\left(\mathrm{Na}^{+}\right)$

- Plateau

Figure 2. Essay Prompt for the Unit Exam: All students were given the same essay prompt, and responses were graded by a rubric

\begin{tabular}{|c|c|c|c|c|c|c|}
\hline \multicolumn{7}{|c|}{ Rubric: Cardiomyocyte Action Potential Essay } \\
\hline Component & 5 & 4 & 3 & 2 & 1 & 0 \\
\hline 1. Vocabulary terms & \begin{tabular}{|l|} 
All 9 vocabulary \\
terms areused \\
appropriately
\end{tabular} & $\begin{array}{l}7-8 \text { vocabulary } \\
\text { terms areused } \\
\text { appropriately }\end{array}$ & $\begin{array}{l}\text { 5-6 vocabulary } \\
\text { terms are used } \\
\text { appropriately }\end{array}$ & $\begin{array}{l}3-4 \text { vocabulary } \\
\text { terms are used } \\
\text { appropriately }\end{array}$ & $\begin{array}{l}1-2 \text { vocabulary } \\
\text { terms are used } \\
\text { appropriately }\end{array}$ & $\begin{array}{l}\text { No vocabulary } \\
\text { terms are used } \\
\text { appropriately }\end{array}$ \\
\hline $\begin{array}{l}\text { 2. Phases of the cardiomyocyte } \\
\text { action potential }\end{array}$ & $\begin{array}{l}\text { All } 3 \text { phases are } \\
\text { appropriately } \\
\text { described }\end{array}$ & $\begin{array}{l}\text { All } 3 \text { phases are } \\
\text { referredto, but } \\
\text { only } 2 \text { phases } \\
\text { were } \\
\text { appropriately } \\
\text { described }\end{array}$ & $\begin{array}{l}\text { Only } 2 \text { phases } \\
\text { were referred to } \\
\text { and appropriately } \\
\text { described }\end{array}$ & $\begin{array}{l}2 \text { phaseswere } \\
\text { referred to, but } \\
\text { only } 1 \text { phasewas } \\
\text { appropriately } \\
\text { described }\end{array}$ & $\begin{array}{l}\text { Only } 1 \text { phasewas } \\
\text { referred to and } \\
\text { appropriately } \\
\text { described }\end{array}$ & $\begin{array}{l}\text { None of the } \\
\text { phaseswere } \\
\text { appropriately } \\
\text { described }\end{array}$ \\
\hline 3. Information & $\begin{array}{l}\text { All information } \\
\text { presented in the } \\
\text { essaywasclear } \\
\text { and accurate }\end{array}$ & $\begin{array}{l}\text { Most information } \\
\text { presented in the } \\
\text { essaywasclear } \\
\text { and accurate }\end{array}$ & $\begin{array}{l}\text { Most information } \\
\text { presented in the } \\
\text { essay was clear, } \\
\text { but there were } \\
\text { some minor } \\
\text { inaccuracies }\end{array}$ & $\begin{array}{l}\text { Some information } \\
\text { was unclear, and } \\
\text { there were minor } \\
\text { inaccuracies }\end{array}$ & $\begin{array}{l}\text { Informationwas } \\
\text { usually not clear } \\
\text { OB had some } \\
\text { major inaccuracies }\end{array}$ & $\begin{array}{l}\text { Informationwas } \\
\text { unclear and had } \\
\text { major } \\
\text { inaccuracies }\end{array}$ \\
\hline $\begin{array}{l}\text { 4. Overall explanation of the } \\
\text { cardiomyocyte action potential }\end{array}$ & \begin{tabular}{|l|} 
The explanation \\
is extremely \\
thorough, with \\
appropriate \\
referenceto the \\
figure \\
\end{tabular} & $\begin{array}{l}\text { The explanation } \\
\text { is thorough, but } \\
\text { neglects to } \\
\text { appropriately } \\
\text { refer to the figure }\end{array}$ & $\begin{array}{l}\text { The explanation } \\
\text { was mostly } \\
\text { thorough, but } \\
\text { was lacking in } \\
\text { understanding in } \\
\text { some areas }\end{array}$ & $\begin{array}{l}\text { The explanation } \\
\text { showed onlya } \\
\text { very basic } \\
\text { understanding of } \\
\text { the material }\end{array}$ & $\begin{array}{l}\text { The explanation } \\
\text { was lacking in } \\
\text { manyareas }\end{array}$ & $\begin{array}{l}\text { The explanation } \\
\text { did not showa an } \\
\text { adequate } \\
\text { understending of } \\
\text { the material }\end{array}$ \\
\hline Total Points Achieved & \multicolumn{6}{|c|}{$/ 20$ points } \\
\hline Overall Percentage & \multicolumn{6}{|c|}{$/ 100 \%$} \\
\hline
\end{tabular}

Student name:

Comments:

Figure 3. Professor-Designed Rubric for the Essay: All student responses were graded using the same rubric 


\subsection{Data Analysis}

The same essay prompt (shown in Figure 2) was given to the treatment and comparison groups. Students were given an opportunity to review the exam after it was graded, but all copies of the test were collected by the professor and were not returned to students to protect against student distribution to other sections or semesters of classes. Following the exam, students given access to the video were asked to complete a 15 question anonymous survey which analyzed their preferred learning strategies, identified any technological issues, and analyzed the effectiveness of the videos. The survey questions consisted of a mixture of forced true/false (yes/no), multiple choice, Likert scale, and open-ended text responses. The survey was administered online using the Qualtrics program (http://www.qualtrics.com), through a link to the classroom Blackboard site.

Statistical analyses were performed using Origin software version 8.1 (OriginLab, Northampton, MA). The mean exam scores were compared for statistical significance with $\mathrm{p}<.05$ using the Student's t-test. This study has been approved through an expedited review from the Institutional Review Board by Valencia College, IRB \# 12-0027.

\section{Results}

Replacement of lecture with the online videos appeared to have a general positive effect on class performance by increasing the class average by $6 \%$ and the class median by $8 \%$ on the essay portion of the exam (Figure 4). The class average on the essay with traditional lecture was $64 \%$ (SD 26, $n=123$ ), and this increased in the treatment group to $71 \%$ (SD 24, $n=54$ ). While this effect was not shown to be statistically significant due to large variance in student scores ( $\mathrm{p}=0.1$, Student's t-test), it nonetheless indicated a general positive effect on overall student performance. The median also increased from $67 \%$ in the comparison group to $75 \%$ in the treatment group.

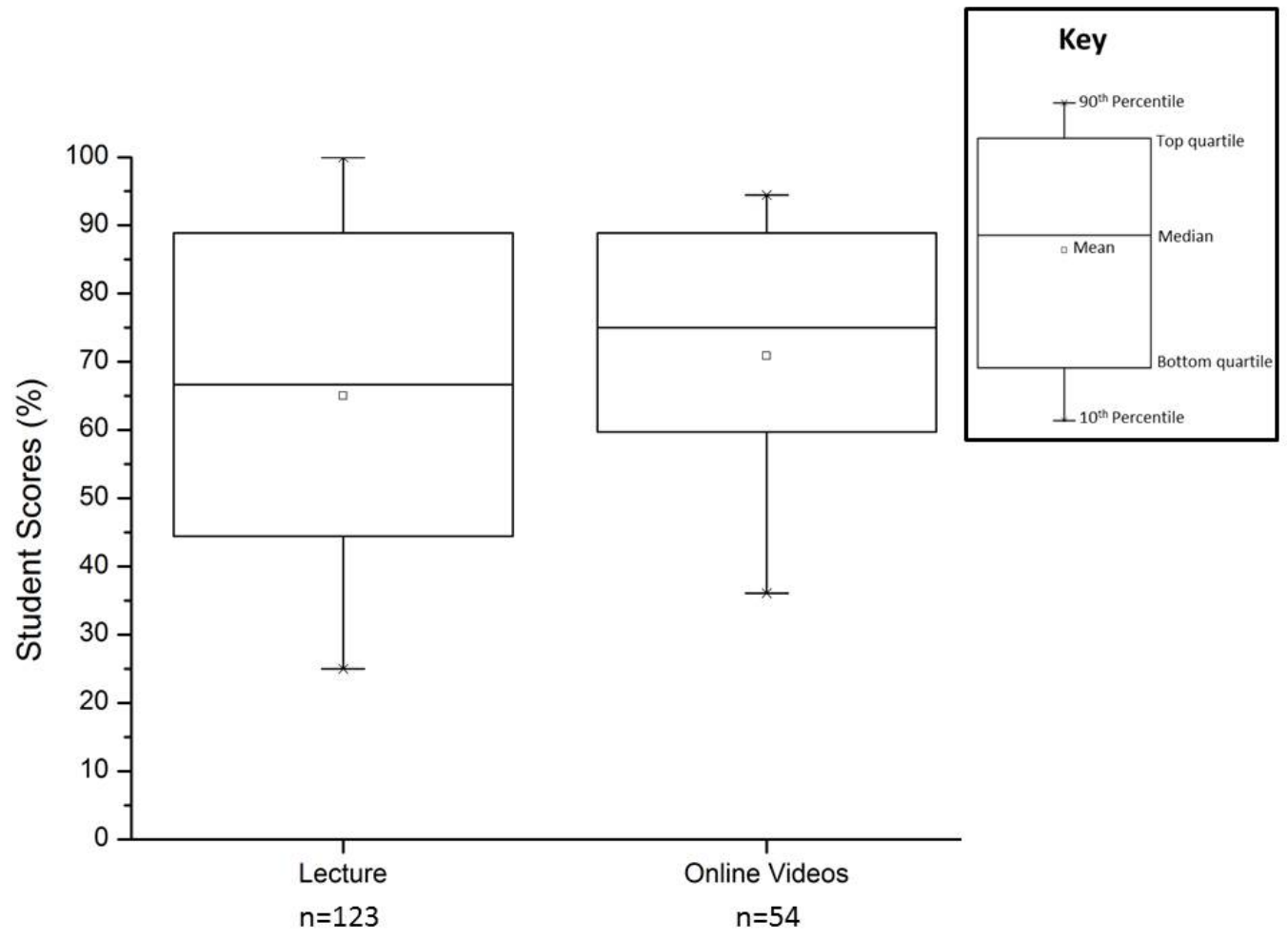

Figure 4. The Effects of Multimedia Videos on Student Success in Anatomy \& Physiology II Courses: Box plot of student percentages on the essay portion of the exam, $n=54-123$

These improvements were not seen among the top-performing students, who scored highly regardless of the delivery method. The $90^{\text {th }}$ percentile of students given traditional lecture versus the video decreased $(100 \%$ vs. $94 \%)$, but there was no change in the top quartile (identical values of 89\%). On the other hand, differences were identified in the poorly performing students in the bottom quartile and $10^{\text {th }}$ percentile. The bottom quartile scores of students exposed to traditional lecture was only $44 \%$, and this was raised to a passing score of $60 \%$ when given video access. The $10^{\text {th }}$ percentile also displayed an improvement from scores of $25 \%$ with traditional lecture to $36 \%$ among those 
students given access to the videos.

In past semesters, which were given a traditional lecture, the overall percentage of failing students on the essay ranged from $31-48 \%$ of the class, with an average in the classes of a $38 \%$ failure rate on the essay (Figure 5A, $\mathrm{n}=123$ ). This failure rate was reduced to $24 \%$ in the semesters of classes that were given access to the online videos (Figure 5B, n=54). Thus, there was a general shift in student performance on the essay towards higher letter grades. There were no significant differences between the treatment and comparison groups on the remaining portions of the unit exam, or in their final letter grades in the course (data not shown, Student’s t-test).
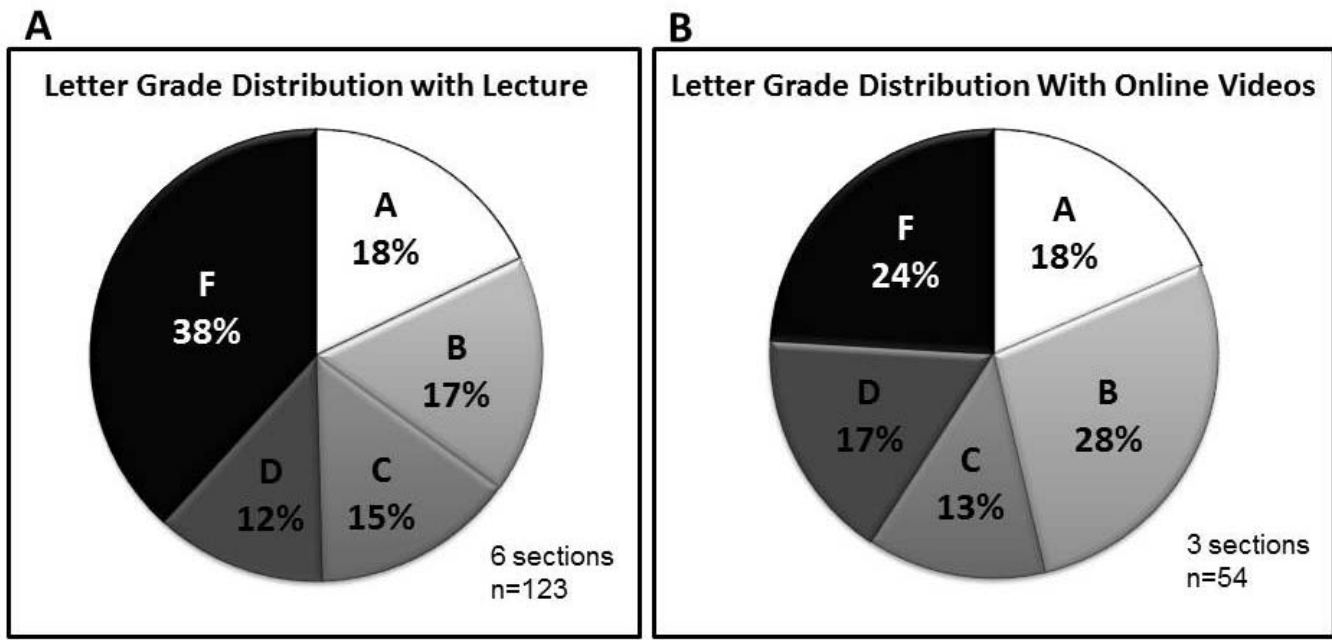

Figure 5. Student Letter Grades on the Unit Exam Essay: Using the students' percentage points on the exam essay, letter grades were assigned: $90-100 \%=A, 80-89 \%=B, 70-79 \%=C, 60-69 \%=D$, and $<60 \%=F$. Scores were rounded up

from .5-.9 to the next whole number. The percentage of students achieving each of the letter grades was then determined. Panel A: Results of 6 sections of students, $n=123$, who were given a traditional didactic lecture and not given access to the videos $\underline{\text { Panel B}}$ : Results of 3 sections of classes, $n=54$, who were given access to the videos

\section{"Through which of the following methods do you feel that you learn challenging Physiology concepts most effectively?"}

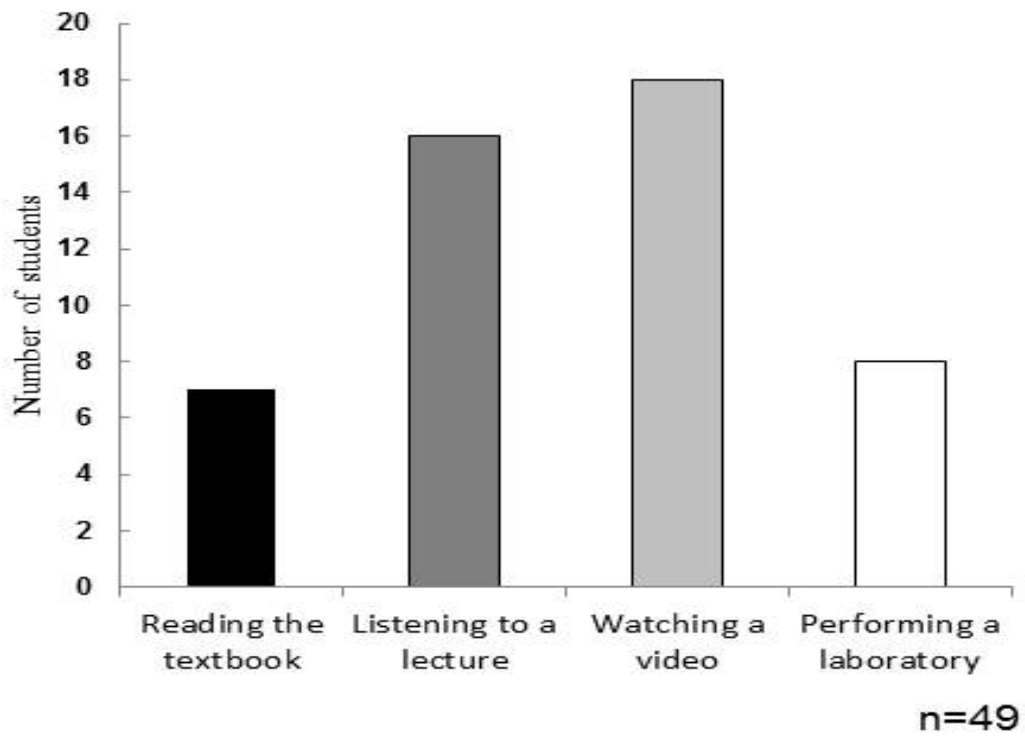

Figure 6. Anonymous Student Survey Results: Response to the prompt: "Through which of the following methods do you feel that you learn challenging Physiology concepts most effectively?” Students were asked to select from the four answer choices listed above. $\mathrm{n}=49$ 
Students in the treatment group were asked to analyze their learning methods on an anonymous survey (Figure 6). Out of the 54 students in the treatment group, 49 students completed the anonymous Qualtrics survey. When responding to a forced prompt on the survey, a large number of the responding students indicated that they learned challenging physiology concepts most effectively through either listening to a lecture (33\%) or watching a video (37\%). A smaller number of students indicated that they learned physiology concepts most effectively by performing a laboratory $(16 \%)$ or reading the textbook (12\%). When students were further prompted to choose between the top two responses, traditional lecture or online videos, 42 out of 49 students indicated that they would prefer a combination of the two teaching styles (Figure 7).

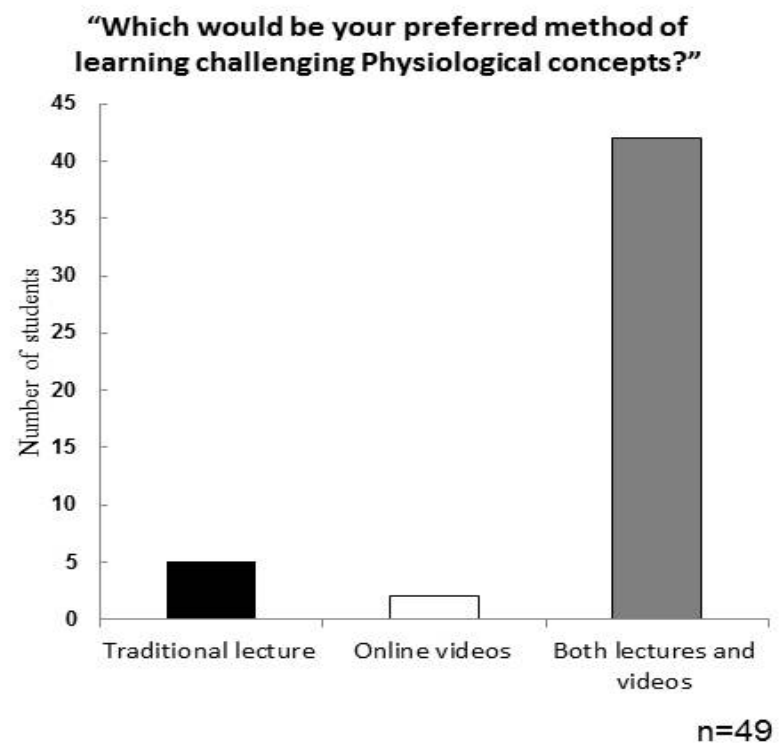

Figure 7. Anonymous Student Survey Results: Response to the prompt: "Which would be your preferred method of learning challenging physiological concepts?" Students were asked to select “traditional lecture,” "online videos,” or "both of the above." $\mathrm{n}=49$

Students not only indicated that the videos were a method by which they learned effectively, but they also recognized an educational benefit of the method. Over $85 \%$ of students indicated that they felt the online videos improved their understanding of the physiological process (Figure 8, $n=49$ ), and $84 \%$ of the students felt that the videos improved their performance on the unit exam (data not shown, $n=49$ ).

\section{"Do you feel that the online videos improved your understanding of the Physiological process?"}

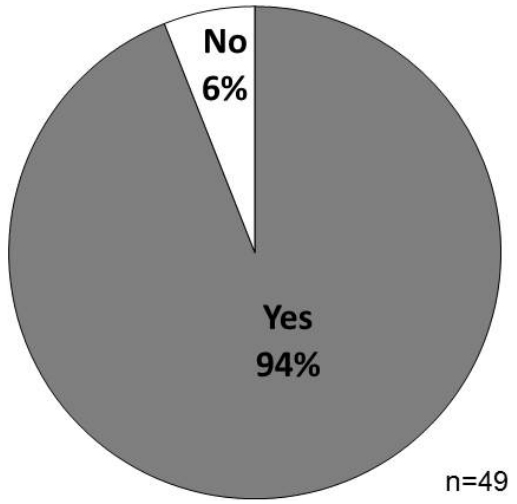

Figure 8. Anonymous Student Survey Results: Response to the prompt: "Do you feel that the online videos improved your understanding of the physiological process" Students were asked to select "yes" or "no." n=49 
When students were asked which aspect of the online videos they found to be most helpful, a large percentage of students indicated the ability to visualize the physiological process (49\%), and to pause and revisit the material as needed (35\%) (Figure 9). The students reported that they did access the video multiple times, with $80 \%$ of the students accessing the video at least twice, and 11 students out of 49 viewing the videos 4 or more times (data not shown). On average, each student accessed the video 3 times (data not shown). This was confirmed through online tracking on the blackboard website.

\section{"Which aspect of the online videos did you find most helpful?"}

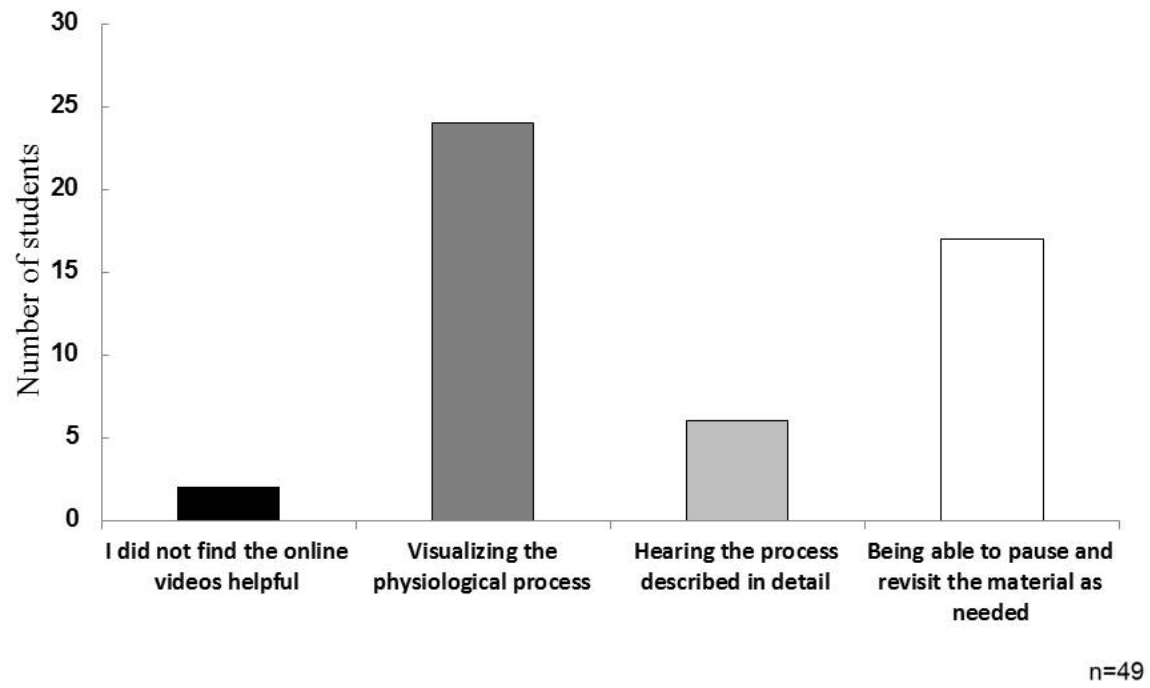

Figure 9. Anonymous Student Survey Results: Response to the prompt: "Which aspect of the online videos did you find most helpful?" Students were asked to select from the four answer choices listed above. n=49

The students also positively evaluated the cardiomyocyte video on the anonymous evaluation forms. Students were asked to respond to the open-ended prompt: "Do you have any further suggestions or comments regarding the use of online videos in this course?" Some selected student comments include:

- $\quad$ "The videos are good because you get a combination of the visual and the detailed description. You may think you know the concept but not know exactly how to explain it. The videos help with that."

- " "A great way to review difficult concepts in our time and repeatedly as needed."

- "For visual learners, such as myself, I do not always grasp the concepts by lecture alone. I need to SEE what is actually happening in order to fully understand."

\section{Discussion}

The drive towards online education has been increasingly rapidly over the past decade, particularly in community colleges. In 2011, online enrollment in community colleges increased by $8.2 \%$, while overall enrollment remained constant (Crawford \& Persaud, 2013). The traditional student entering college, as a digital native, has grown up with computers, smart phones, tablets, and online videos (Levine \& Dean, 2012). Given the prevalence of these tools in their daily lives, it would seem to be a natural progression to the entry of technology into the modern classroom. However, it may be difficult for faculty to ascertain whether a teaching method is preferred by students versus whether a given teaching tool results in better mastery of the material. Ideally, the two would be one and the same, and that is indeed what was found in this study. Students anonymously self-reported that a larger percentage learned most effectively through online videos compared to other learning techniques (37\%), and this tool also appeared to increase at-risk student performance. There was a slight improvement in the overall average for an exam essay by $6 \%$ when using the online videos, but there were drastic improvements in student scores in the bottom quartile by $15 \%$.

While the results of the study were not statistically significant, there was a trend that indicated an improvement in the scores. Although it was not possible given the context of this study, a larger sample size could have potentially increased the power of the statistics to a significant level. However, it must also be recognized that the large 
variability in student exam performance, throughout the college, makes statistical significance a difficult goal to achieve.

There were no significant differences seen between the treatment and comparison groups on the other portions of the unit exam, or in their final grades in the course. This is not surprising given the small contribution of the essay toward the student's overall grade (1\% of final letter grade in the course). Thus, although the intervention in this pilot study was brief, the trend of increased performance in the bottom quartile of students suggests that online multimedia resources may have a positive influence on student performance and should be further investigated.

On the other hand, it is always a concern that a new teaching tool may be harmful to students who have already successfully mastered the typical classroom methods. In this study, there was a drop in the 90th percentile of students when the videos were used (6\%), but no change at all in the upper quartile between the two methods. It would be useful in future studies to continue examining both ends of the performance spectrum, to ensure that the top students are not harmed by accessory learning methods. This could become particularly important as the magnitude of online content is increased in the course.

Given the busy schedule of today's professor, it is also imperative to analyze the benefits of a new educational technique versus the time invested in its conception and execution. While the creation of Camtasia videos can be time-consuming for the professor, there are numerous benefits to creating custom videos for use in the classroom. Perhaps most importantly, the creation of novel Camtasia videos allows the professor to control video content. On the survey, $84 \%$ of the polled students indicated that they accessed outside physiological videos sources using search engines in their science courses (data not shown). These videos may contain outdated or inaccurate information, or may not be at an appropriate content level. By carefully designing their own videos, faculty members are able to emphasize the important concepts needed for success in the course.

It could be hypothesized that the increased student success when given online videos was due to an increased time-on-task. However, the duration of the videos was approximately ten minutes, and each student accessed them an average of three times for a total of 30 minutes on task. It typically requires around 30 minutes of class time in which to lecture on this topic due to the need for repetition, student questions, and attempts to explain a static figure in a dynamic fashion. Consequently, the duration of the two methods, and thus the time-on-task was approximately equal. It is possible, however, that students were more motivated to study outside of the class on the topic, which should be examined in future studies. The 30 minutes of valuable class time, which was saved by moving the class content online, could be used for collaborative, active, or other important learning methods in the classroom.

While this study focused on the complete replacement of didactic lecture with an online video, there may be additional advantages to creating complementary in-class activities to reinforce the video content. Of the polled students, $86 \%$ indicated that they preferred a combination of traditional lecture and videos when learning challenging physiological concepts. The presentation of lecture material in an online format could be useful in the "flipped classroom" curricular approach currently being employed at many schools. Students are given the opportunity to access key content information online, outside of class time, and class meetings are used for problem-solving, discussions, or other applications of the material. The "flipped" classroom format has been indicated to improve the quality of student learning, as well as student engagement in the classroom (Bates \& Galloway, 2012; Miller, McNear, \& Metz, 2013). Research from the National Center for Education Statistics indicates that, even at the K-12 level, engagement in the course material and with peers in the classroom is important for the success of at-risk students (Finn, 1993).

Although this study showed an improvement in the number of failing students, it did not identify which groups of at-risk students benefited the most. Online materials could have different benefits and risks for non-traditional students, student with learning or mental disabilities, or students for which English is not their first language. The highly visual nature of the videos may have specific benefits for some groups of at-risk students versus others. Indeed, studies have shown different learning styles among racial and ethnic groups, generations of students, and mildly handicapped students (Brunner \& Majewski, 1990; Dunn \& Griggs, 1990; Oblinger, 2003). These different learning preferences, along with other factors, could influence the impact that online videos have on student performance.

For example, non-traditional students may prefer the online format because it allows them to incorporate classroom material into their hectic schedules (Dykman \& Davis, 2008). These students may exhibit higher rates of absenteeism, and thus a hybrid format may be beneficial to their needs. However, non-traditional students may also lack basic computer skills, thus computer-training should be available to those who require it. 
At-risk students with learning or mental disabilities often have difficulty succeeding in the traditional classroom setting. The Camtasia program incorporates Universal Design concepts through the use of closed-captioning and other ADA compliant programming. Camtasia videos have been shown in the literature to assist students with learning disabilities with their note-taking skills, study habits, and test performance (Graves \& Plant, 2009).

For those students who do not speak English as their first language, the videos may permit them to immerse themselves in complicated scientific vocabulary, or allow them to visualize the processes for which they would have difficulty understanding from written explanations. In language acquisition courses, online content has been shown to increase student confidence, motivation, and interaction with their classmates and instructor (Lai \& Kritsonis, 2006). On the other hand, there are some concerns that online formats may prevent students from properly developing communication skills of reading and writing (Kimmel \& Deek, 1996). Given that the exam format for this study was an essay, our results do not suggest that the online videos resulted in a drop in written communication skills.

Thus, there are many reasons why individual groups of at-risk students may benefit from the use of multimedia resources. Work by Richard Mayer on multimedia learning suggests that there may general benefits for any student who has low prior knowledge of a specific concept (1997). While all students in this study had successfully passed an Anatomy and Physiology I course, there may be differences in their exposure to, and comprehension of more advanced course concepts. Additionally, higher performing students may be able to mentally produce their own animations from static diagrams, reducing the necessity of multimedia resources (Hegarty, Kriz, \& Cate, 2003).

\section{Conclusion}

In conclusion, the results of this pilot study suggest that the replacement of traditional lectures with online videos, when done carefully and deliberately, has potential benefits for high-risk student populations. The realm of online learning may provide an avenue to reach low-performing students and mitigate the poor retention rates seen for at-risk students in colleges and universities across the nation. While many institutions are exploring remedial programs and other academic support systems for struggling students, online learning modules could be created to reach a large number of students with low cost expenditures. By providing students with a safe, online environment in which to explore complex topics, we may not only improve student scores, but also develop the lifelong learning skills necessary to succeed in the modern world. It is worth noting that many other qualitative benefits were observed during the study, including: an increase in student confidence with the material, an improved use of the terminology, and more positive interactions between the professor and students. These results indicate a need to further examine the implementation of web-based learning, with particular focus on the benefits or risks for specific groups of at-risk students.

\section{Acknowledgements}

Dr. Cynthia Miller is currently an Assistant Professor in the Department of Physiology \& Biophysics, University of Louisville, Louisville, KY. The author would like to thank Mr. Tim Grogan, Professor of Biology at Valencia College, who assisted with the planning of this project. This paper was completed as part of the Biology Scholars Program (BSP) Transitions Residency, funded in part by the National Science Foundation and sponsored by the American Society for Microbiology.

\section{References}

Ainsworth S., \& Van Labeke N. (2004). Multiple forms of dynamic representation. Learning and Instruction, 14(3), 241-255. http://dx.doi.org/10.1016/j.learninstruc.2004.06.002

Alberts B. (2009). Restoring science to science education. Issues in Science \& Technology, 25(4), 77-80.

Bates S., \& Galloway R. (2012). The inverted classroom in a large enrollment introductory Physics course: a case study. The Higher Education Academy.

Blevins A., \& Elton C.W. (2009). An evaluation of three tutorial-creating software programs: Camtasia, PowerPoint, and MediaSite. Journal of Electronic Resources in Medical Libraries, 6(1), 1-7. http://dx.doi.org/10.1080/15424060802705095

Brunner C.E., \& Majewski W.S. (1990). Mildly handicapped students can succeed with learning styles. Educational 
Leadership, 48(2), 21-23.

Chumley-Jones H.S., Dobbie A., \& Alford C.L. (2002). Web-based learning: sound education method or hype? A Review of the Evaluation Literature. Academic Medicine, 77(10), S86-S93. http://dx.doi.org/10.1097/00001888-200210001-00028

Cox C. (2004). From cameras to Camtasia: streaming media without the stress. Internet Reference Services Quarterly, 9(3-4), 193-200. http://dx.doi.org/10.1300/J136v09n03_14

Crawford C., \& Persaud C. (2013). Community Colleges Online. Journal of College Teaching and Learning, 10(1), 75-82.

Drysdale M.T.B., Ross J.L., \& Schulz R.A. (2001). Cognitive learning styles and academic performance in 19 first-year university courses: successful students versus students at risk. Journal of Education for Students Placed at Risk, 6(3), 271-289. http://dx.doi.org/10.1207/S15327671ESPR0603_7

Dunn R., \& Griggs S.A. (1990). Research on the learning style characteristics of selected racial and ethnic groups. Journal of Reading, Writing, and Learning Disabilities International, 6(3), 261-280. http://dx.doi.org/10.1080/0748763900060305

Duran R.P. (1989). Assessment and instruction of at-risk Hispanic students. Exceptional Children, 56, 154-158.

Dykman C.A., \& Davis C.K. (2008). Online education forum part 1-the shift toward online education. Journal of Information Systems Education, 19(1), 11-16.

Ely E.E. (1997). The Non-Traditional Student. Paper presented at the American Association of Community College Annual Conference.

Finn J.D. (1993). School engagement and students at risk. National Center for Education Statistics, U.S. Department of Education.

Goldberg H.R., \& McKhann G.M. (2000). Student test scores are improved in a virtual learning environment. Advanc in Physiol Edu, 23, 59-66.

Goldberg H.R., Haase E., Shoukas A., \& Schramm L. (2006). Redefining classroom instruction. Advanc in Physiol Edu, 30, 124-127. http://dx.doi.org/10.1152/advan.00017.2006

Graves L., \& Plant S. (2009). The impact of tablet PCs and pen-based technology on education (R.H. Reed \& D.A. Berque, Eds.). West Lafayette, IN: Purdue University Press.

Hegarty M. (2004). Dynamic visualizations and learning: getting to the difficult questions. Learning and Instruction, 14, 343-351. http://dx.doi.org/10.1016/j.learninstruc.2004.06.007

Hegarty M., Kriz S., \& Cate C. (2003). The roles of mental animations and external animations in understanding mechanical systems. Cognition \& Instruction, 21, 326-360. http://dx.doi.org/10.1207/s1532690xci2104_1

Heisserer D.L., \& Parette P. (2002). Advising at-risk students in college and university settings. College Student Journal, 36(1), 69-84.

Hoffler T.N., \& Leutner D. (2007). Instructional animation versus static pictures: A meta-analysis. Learning and Instruction, 17, 722-738. http://dx.doi.org/10.1016/j.learninstruc.2007.09.013

Kimmel H., \& Deek F. (1996). Instructional technology: a tool or a panacea? Journal of Science Education and Technology, 5, 87-92. http://dx.doi.org/10.1007/BF01575474

Lai C.C., \& Kritsonis W.A. (2006). The advantages and disadvantages of computer technology in second language acquisition. Nat Journal for Publishing and Mentoring Doctoral Student Research, 3, 1-6.

Levine A., \& Dean D.R. (2012). Generation on a tightrope: A portrait of today's college student (3rd ed.). San Francisco, CA: Jossey-Bass Publishing.

Lin Y.H., Liang J.C., \& Tsai C.C. (2012). Effects of different forms of physiology instruction on the development of students' conceptions of and approaches to science learning. Adv in Physio Edu, 36(1), 42-47. http://dx.doi.org/10.1152/advan.00118.2011

Marks S.R. (2004). Personalizing the online classroom using Tech-Smith's Camtasia or Microsoft's Windows Media Encoder. Online Classroom, July, 4-5.

Mayer R.E. (1997). Multimedia learning: Are we asking the right questions? Educational Psychologist, 32(1), 1-19. http://dx.doi.org/10.1207/s15326985ep3201_1 
Mayer, R.E. (2009). Multimedia Learning ( $2^{\text {nd }}$ ed). New York, NY: Cambridge University Press. http://dx.doi.org/10.1017/CBO9780511811678

McFarlin B.K. (2008). Hybrid lecture-online format increases student grades in an undergraduate exercise physiology course at a large urban university. Advanc in Physiol Edu, 32, 86-91. http://dx.doi.org/10.1152/advan.00066.2007

Miller C.J. (2012a). Where does that ion go? A video of the cardiomyocyte action potential: part 1. APS Archive of Teaching Resources. Retrieved from http://www.apsarchive.org/resource.cfm?submissionID=6043

Miller C.J. (2012b). Where does that ion go? A video of the cardiomyocyte action potential: part 2. APS Archive of Teaching Resources. Retrieved from http://www.apsarchive.org/resource.cfm?submissionID=6044

Miller C.J., McNear J., \& Metz M.J. (2013). A Comparison of Traditional and Engaging Lecture Methods in a Large, Professional-Level Course. Adv Physiol Edu, 37, 347-355. http://dx.doi.org/10.1152/advan.00050.2013

Miller, C.J., Aiken S., \& Metz M.J. (“in press”). Perceptions of D.M.D. Student Readiness for Basic Science Courses in the United States: Can Online Review Modules Help? European Journal of Dental Education.

Oblinger D. (2003). Boomers, gen-Xers, and millenials: understanding the "new students.” EDCAUSE Review, 38(4), 36-40.

Office of Educational Research and Improvement. (2002). Helping at-risk students meet standards: a synthesis of evidence-based classroom practices. U.S. Department of Education.

Reed R. (2003). Streaming technology improves achievement. T.H.E. Journal, 30, 7.

Riffell S., \& Sibley D. (2005). Using web-based instruction to improve large undergraduate biology courses: an evaluation of the hybrid course format. Computers \& Education, 44, 217-235. http://dx.doi.org/10.1016/j.compedu.2004.01.005

Sowan A.K., \& Jenkins L.S. (2013). Use of the seven principles of effective teaching to design and deliver an interactive hybrid nursing research course. Nursing Education Perspectives, 34(5), 315-322. http://dx.doi.org/10.5480/1536-5026-34.5.315

Sullivan, P. (2001). Gender Differences and the online classroom: Male and female college students evaluate their experiences. Community College Journal of Research and Practice, 25, 805-818. http://dx.doi.org/10.1080/106689201753235930

Valencia College Institutional Research Department. (2010). Strategic indicators report 2010: selected trends and state comparisons.

Valencia College Institutional Research Department. (2012). Statistical history fact book 2010/2011.

Woo M.A., \& Kimmick J.V. (2000). Comparison of Internet versus lecture instructional methods for teaching nursing research. Journal Prof Nurs, 16, 132-139. http://dx.doi.org/10.1053/PN.2000.5919 